\title{
The comfort parameters in indoor air of sports facilities with different ventilation regimes
}

\author{
Cátia Peixoto ${ }^{1}$, Klara Slezakova ${ }^{2}$, Maria do Carmo Pereira ${ }^{3}$ and Simone Morais
}

\begin{abstract}
REQUIMTE-LAQV, Porto School of Engineering, Polytechnic of Porto, PT; LEPABE, Department of Chemical Engineering, Faculty of Engineering, University of Porto, PT (catia.peixoto@graq.isep.ipp.pt) ORCID 0000-0002-2957-7458, ${ }^{2}$ LEPABE Department of Chemical Engineering, Faculty of Engineering, University of Porto, PT (slezakok@fe.up.pt) ORCID 0000-0001-5265-4186, 32LEPABE, Department of Chemical Engineering, Faculty of Engineering, University of Porto, PT (mcsp@fe.up.pt) ORCID 0000-0001-8505-3432, REQUIMTE-LAQV, Porto School of Engineering, Polytechnic of Porto, PT (sbm@isep.ipp.pt) ORCID 0000-0001-6433-5801.
\end{abstract}

https://doi.org/10.24840/978-972-752-279-8_0037-0042

\begin{abstract}
Introduction: In Portugal, during COVID19 pandemic, sport and fitness facilities were closed. When lockdown has been lifted, in order to prevent the spread of infection, indoor sport facilities were subject to specific regulations that limited indoor occupancy as well as manner of air ventilation. This study aims to analyze the impacts of these ventilation restrictions on indoor air comfort parameters in sport fitness facilities. Methodology: Temperature $(\mathrm{T} ; \stackrel{\circ}{\circ} \mathrm{C})$, relative humidity $(\mathrm{RH} ; \%)$, and carbon dioxide $\left(\mathrm{CO}_{2}\right)$ were continuously monitored (41 days; spring and autumn) in four fitness centers situated in Oporto metropolitan area: two of them under normal ventilation conditions (i.e. before lockdown; NV1 and NV2) and two of them under temporary restrictions for indoor ventilations and occupancy (RV1 and RV2). Results and Discussion: Under normal ventilation conditions, $T$ in fitness centers slightly varied (in NV1:22-25 ㄷ; NV2: 20-23 ${ }^{\circ} \mathrm{C}$ ) but in both clubs the comfort recommendations $(18-25 \circ \mathrm{C})$ were fulfilled. On contrary, RH were below guideline values (55-75\%) in NV1 (47-54\%) whereas at NV2 (66-73\%) it fulfilled the recommendations. When specific health regulations took place, mean T ranges were similar in both clubs (RV1: 21-23 ㄷ; RV2:21-23 ${ }^{\circ}$ ) but they both exceeded recommended comfort levels (16-21 o C). Mean RH were in accordance with the legislative values, but the very high temporal maxima (up to 75 and $89 \%$ ) indicate the possible discomforts the that exercisers might have experienced. Concerning the $\mathrm{CO}_{2}$, the obtained results showed that indoor levels decreased when specific health restrictions were in force (11-121\%) most likely due imposed guidelines for human occupancy. Conclusions: The restrictions for ventilation and human occupancy positively impacted indoor levels of $\mathrm{CO}_{2}$. However, $\mathrm{T}$ and $\mathrm{RH}$ were on several occasions outside the recommended comfort levels, especially during group activity classes. As regular exercising in environmental conditions, such as elevated $\mathrm{T}$ and increased $\mathrm{RH}$ can cause health discomforts, these parameters should be carefully maintained within the recommended ranges even under restricted ventilation scenarios.
\end{abstract}

Keywords. Indoor air quality (IAQ), Carbon dioxide $\left(\mathrm{CO}_{2}\right)$, Comfort parameters, Temperature (으), Relative humidity (\%HR).

\section{INTRODUCTION}

Physical activity is an important factor for quality of life; frequent practice of exercise, such as walking or bicycling, presents great heath benefits (Warburton et al., 2006). A clean environment is also essential for human health and well-being. Considering the environmental perspective, one of the most relevant health concerns is related with air quality in spaces in which people spend their time, both indoor and outdoor (EEA, 2011; Almeida et al., 2014). In Portugal during the SarsCov-2 pandemic, sport and fitness facilities were closed. After the lockdown, in order to prevent a spread of infections, these indoor spaces were subjected to specific health recommendations, namely in terms of type of ventilation and restrictions for occupancy. In sport facilities, this was also applied to occupancy, habits and behaviors during individual trainings as well to group-activity classes. This study aims to analyze the impacts of these restrictions on indoor air comfort parameters, namely temperature $(T)$, relative humidity $(\mathrm{RH})$, and carbon dioxide $\left(\mathrm{CO}_{2}\right)$ in four fitness centers, two of them being monitored under normal ventilation conditions (NV1 and NV2) and two after the lockdown under temporary health restrictions (RV1 and RV2). 


\section{METHODOLOGY}

The data collection for this was carried out in two phases. The first part of sampling was carried out in two fitness centers (NV1 and NV2) before the virus outbreak under normal conditions. The sampling was done continuously, during 21 consecutive days (including weekdays and weekends) in spring season. NV1-NV2 were large, sophisticated health clubs (internationally recognized) and were equipped with pool. The second phase of this work was conducted in autumn season 2020, for 20 consecutive days in fitness centers (RV1 and RV2) with restrictions for ventilation and indoor space occupancies. These clubs belong to a chain of low-cost gyms and, on contrary to the previous, RV1-RV2 did not have pools. However, the indoor layout in four clubs were similar and included: (i) a bodybuilding and cardio fitness area, (ii) two-three studios for group classes, and a cycling class studio. The four clubs were situated Oporto Metropolitan Area; road traffic and local industry were the main sources in ambient air of the respective sites (Pereira et al., 2007; Slezakova, 2013). Mechanical ventilation was provided through HVAC system that controls ventilation and air temperature; at the time of second phase of sampling the system was allowed to provide only ventilation (in a limited manner). The number of people (after lockdown, phase two) in indoor spaces was controlled and reduced.

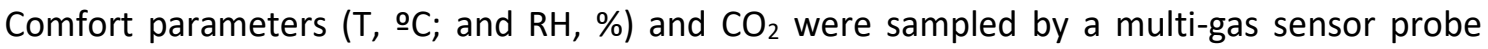
(model TG 502; GrayWolf Sensing Solutions, Shelton, USA) continuously, with 1 min logging interval. Samplers were mounted on supports $(1.4 \pm 0.2 \mathrm{~m})$ and at least $1.5 \mathrm{~m}$ from walls to minimize the influence on pollutant dispersion (Holmberg et al., 1998; Jin et al., 2013), location of samplers was chosen in order to avoid any direct influence (opened windows/doors, mechanical ventilation systems, cleaning product emissions, etc.).

\section{RESULTS AND DISCUSSION}

\section{$\underline{\mathrm{CO}_{2}}$}

Under normal conditions, the overall average $\mathrm{CO}_{2}$ concentration was $3333 \mathrm{mg} / \mathrm{m}^{3}$, with values ranging between $1048-7671 \mathrm{mg} / \mathrm{m}^{3}$ in club NV1. The corresponding levels in NV2 were 1304 $\mathrm{mg} / \mathrm{m}^{3}$ (mean) and range of $686-4907 \mathrm{mg} / \mathrm{m}^{3}$. In club NV1, the averages obtained across indoor spaces (general area, studios) were above the limit value $\left(2250 \mathrm{mg} / \mathrm{m}^{3}\right)$ of Portuguese legislation thus indicating insufficient ventilation (Slezakova et al., 2018). Furthermore, the stricter recommendation of the American Society of Heating, Refrigerating, and Air-Conditioning Engineers (ASHRAE; $1800 \mathrm{mg} / \mathrm{m}^{3}$ ) (Persily, 1997) was exceeded too. Considering human occupancy, the corresponding obtained mean in NV1 was $3770 \mathrm{mg} / \mathrm{m}^{3}$ (approximately 1.7 times higher than the protection threshold) when people frequented them vs. $2659 \mathrm{mg} / \mathrm{m}^{3}$ when they were closed. When analyzing different indoor spaces, average concentration $\left(4657 \mathrm{mg} / \mathrm{m}^{3}\right)$ that was twice higher than the threshold in body building and cardio fitness area; the respective temporal maxima reached value of $7671 \mathrm{mg} / \mathrm{m}^{3}$, surpassing (3.4 times) the limit. For studios, mean $\mathrm{CO}_{2}$ was $3299 \mathrm{mg} / \mathrm{m}^{3}$, exceeding 1.5 times the legal limit. Furthermore, type of activity impacted the indoor $\mathrm{CO}_{2}$ as the highest levels were recorded during classes with more vigorous exercises. In club NV2, the mean $\mathrm{CO}_{2}$ levels obtained in different spaces fulfilled the limit value of $2250 \mathrm{mg} / \mathrm{m}^{3}$, with exception to group studios (when occupied: mean value of $2481 \mathrm{mg} / \mathrm{m}^{3}$ ). Although ventilation setups and routines were similar in both gyms, in NV2 its better control, the overall more spacious rooms, and limited occupancy (strict control and registry for group classes) led to lower (about $60 \%$ less) overall $\mathrm{CO}_{2}$ levels. During the second phase, after lockdown when ventilation and occupancy restrictions were applied in indoor spaces, average $\mathrm{CO}_{2}$ was $1400 \mathrm{mg} / \mathrm{m}^{3}$ (range $122-2894 \mathrm{mg} / \mathrm{m}^{3}$ ) in RV1 and $1543 \mathrm{mg} / \mathrm{m}^{3}\left(739-6740 \mathrm{mg} / \mathrm{m}^{3}\right.$ ) in RV2. When occupied indoor $\mathrm{CO}_{2}$ were slightly (though not significantly; $\mathrm{p}=0.05$ ) higher than 
when closed. The temporal maxima (RV1: $2660-2894 \mathrm{mg} / \mathrm{m}^{3}, \mathrm{RV} 2: 2798-6740 \mathrm{mg} / \mathrm{m}^{3}$ ) exceeded the protection threshold defined in Portuguese legislation in the two gyms, but in RV2 obtained values were 2.3 times higher. Concerning the group activities in $\mathrm{RV} 2$, mean $\mathrm{CO}_{2}$ exceeded the value defined in the legislation in highly intense cardiovascular (bodyjump: $3533 \mathrm{mg} / \mathrm{m}^{3}$ ) and cycling classes (cycling: $3742 \mathrm{mg} / \mathrm{m}^{3}$ ). Whereas $\mathrm{CO}_{2}$ is does not pose hazard to human health at the levels detected in clubs, exposure to moderate concentrations can cause changes in human performances and influence decision-making (Persily, 1997; Satish et al., 2012). Thus, despite the restrictions in the number of occupants, $\mathrm{CO}_{2}$ concentration during the high intensity group activities were still exceeded.
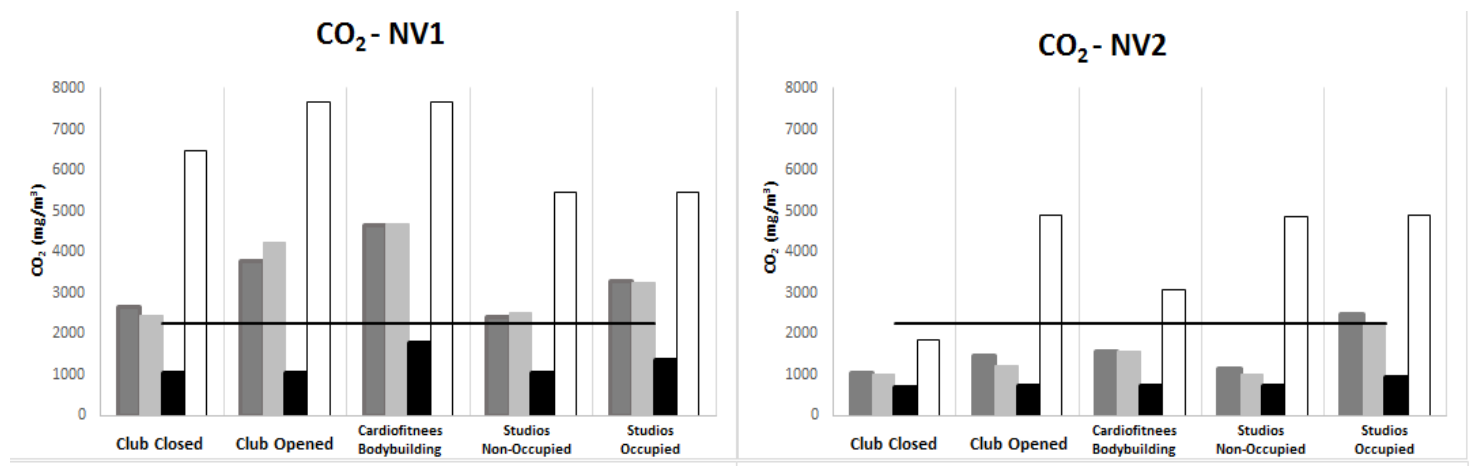

$\mathrm{CO}_{2}-\mathrm{RV} 1$

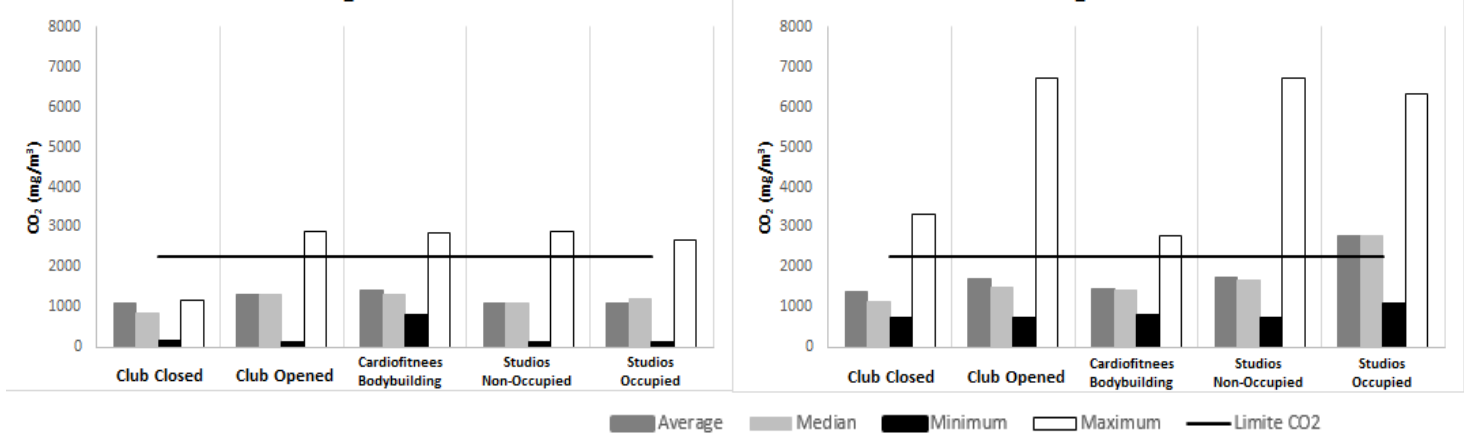

Figure 1. $\mathrm{CO}_{2}$ levels in four fitness clubs under normal ventilations (NV1, NV2) and under restricted ventilations and occupancy (RV1, RV2).

Temperature and relative humidity

$\mathrm{T}$ and $\mathrm{RH}$ are parameters that affect thermal comfort of respective occupants. In general, $\mathrm{RH}$ levels recommended by different organizations range from 30 to $60 \%$. For $\mathrm{RH}$ in range of 30 and $60 \%$, American Society of Heating (ASHRAE) recommends indoor T range of $23.0-25.8$ 으 (ASHRAE, 2017). However, specifically for sport facilities, $\mathrm{RH}$ in range of $55-75 \%$ and $\mathrm{T}$ range of $18-25^{\circ} \mathrm{C}$ (summer) and 16-21으 (winter) are recommended (SEJD, 2008). The spring season was characterized by lower than normal average precipitation $(192 \mathrm{~mm}$ ) of ambient air and higher average air temperature (mean of $14.9^{\circ} \mathrm{C}$ ). In the respective 20 days of sampling maximum daily temperature were high $\left(>30^{\circ} \mathrm{C}\right)$, with a sharp drop. The autumn season was cold and rainy, with mean of ambient air temperature $15.4^{\circ} \mathrm{C}$ (means of $9.9^{\circ} \mathrm{C}$ and $20.8^{\circ} \mathrm{C}$ for the of minimum and maximum air temperature, respectively; IPMA, 2020). Although NV1 and NV2 were both normally ventilated using HVAC systems, they exhibited different indoor temperature ranges. In NV1, when occupied, T ranged between 22.4-25.4 ${ }^{\circ} \mathrm{C}$, while in NV2 it was less, with values of 19.8-22.7 으. This fact can be associated with several factors. Firstly, NV1 was located in the 
basement of a building (at the level of the garages) whereas NV2 was situated on the top floor of a shopping center. In addition, NV2 has much larger room spaces than NV1 (mainly in the cardio and fitness room, which was almost 4 times larger) thus easily accommodating for $T$ increases due to human body of room occupants, as was previously reported (Žitnik et al., 2016). Finally, the control of the number of people was stricter and more effective in NV2, with a permitted limit for each area. Under the restricted conditions, T was almost unchanged when occupied and closed. Means of $22.8{ }^{\circ} \mathrm{C}$ and $21.6{ }^{\circ} \mathrm{C}$ were observed in RV1 and RV2 when closed,

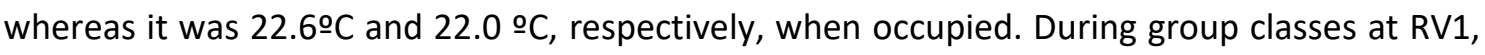
lower temperature values $(17.7 \mathrm{O} C$ ) were obtained due sporadic use of air conditioning system. Nevertheless, it is necessary enhance that mean temperature recorded in both RV1, RV2 did not fulfill the recommendations, being constantly higher than comfort limits, with maxima values up to 24-25.7 ${ }^{\circ} \mathrm{C}$ in $\mathrm{A} 1$ and 23.2-24.6 ${ }^{\circ} \mathrm{C}$ in RV2.

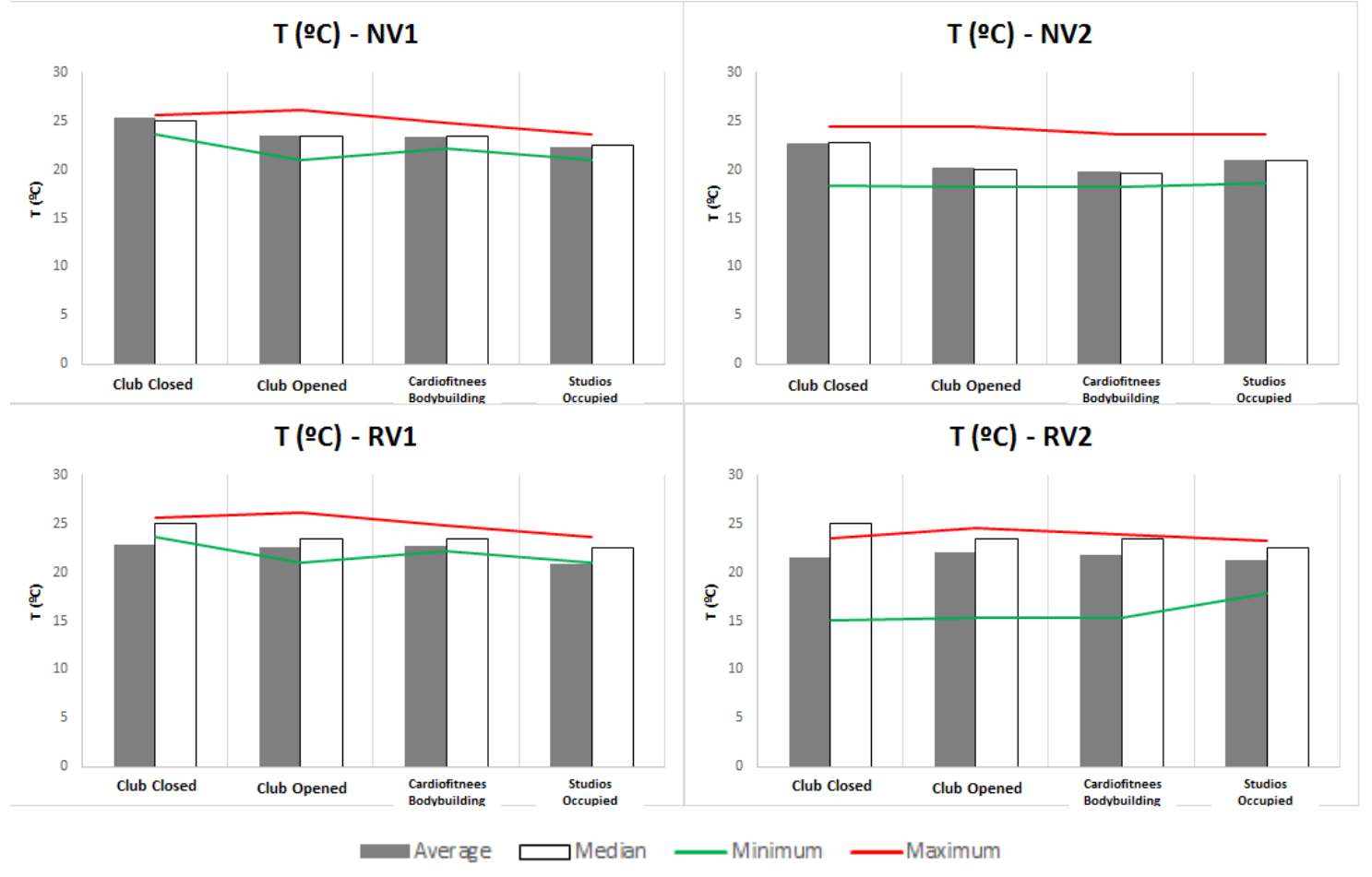

Figure 2. Temperature $(\stackrel{\circ}{\circ})$ in four fitness clubs under normal ventilations (NV1, NV2) and under restricted ventilations and occupancy (RV1, RV2).

When exercising, breathing and perspiration generate substantial amount of water vapor, which impacts measured RH (Žitnik et al., 2016). Under normal ventilation conditions, the average values of $\mathrm{RH}$ recorded at B1 (when occupied, 47-54\%), were always below the recommended minimum designated for sport facilities (SEJD, 2008). Somewhat lower RH can cause some discomfort (drying nose, throat, mucous membranes and skin) (Sylvester et al., 2016; Bélanger et al., 2014). In NV2 (both when occupied and non-occupied) RH was within the recommended guidelines (62-73\%). Under the restricted conditions, higher $\mathrm{RH}$ values were recorded when people exercised, mainly during group classes. The mean $\mathrm{RH}$ in bodybuilding and cardio fitness area was $57 \%$ in RV1 and $62 \%$ in RV2. Furthermore, these values were slightly higher during group activities with average $\mathrm{RH}$ of $63 \%$ and $66 \%$, respectively. Thus, the average values were in accordance with the comfort guidelines though high temporal maxima (75\% in RV1; 89\% in RV2) 
that were occasionally registered indicate the necessity for comfort parameters monitoring in sport facilities.

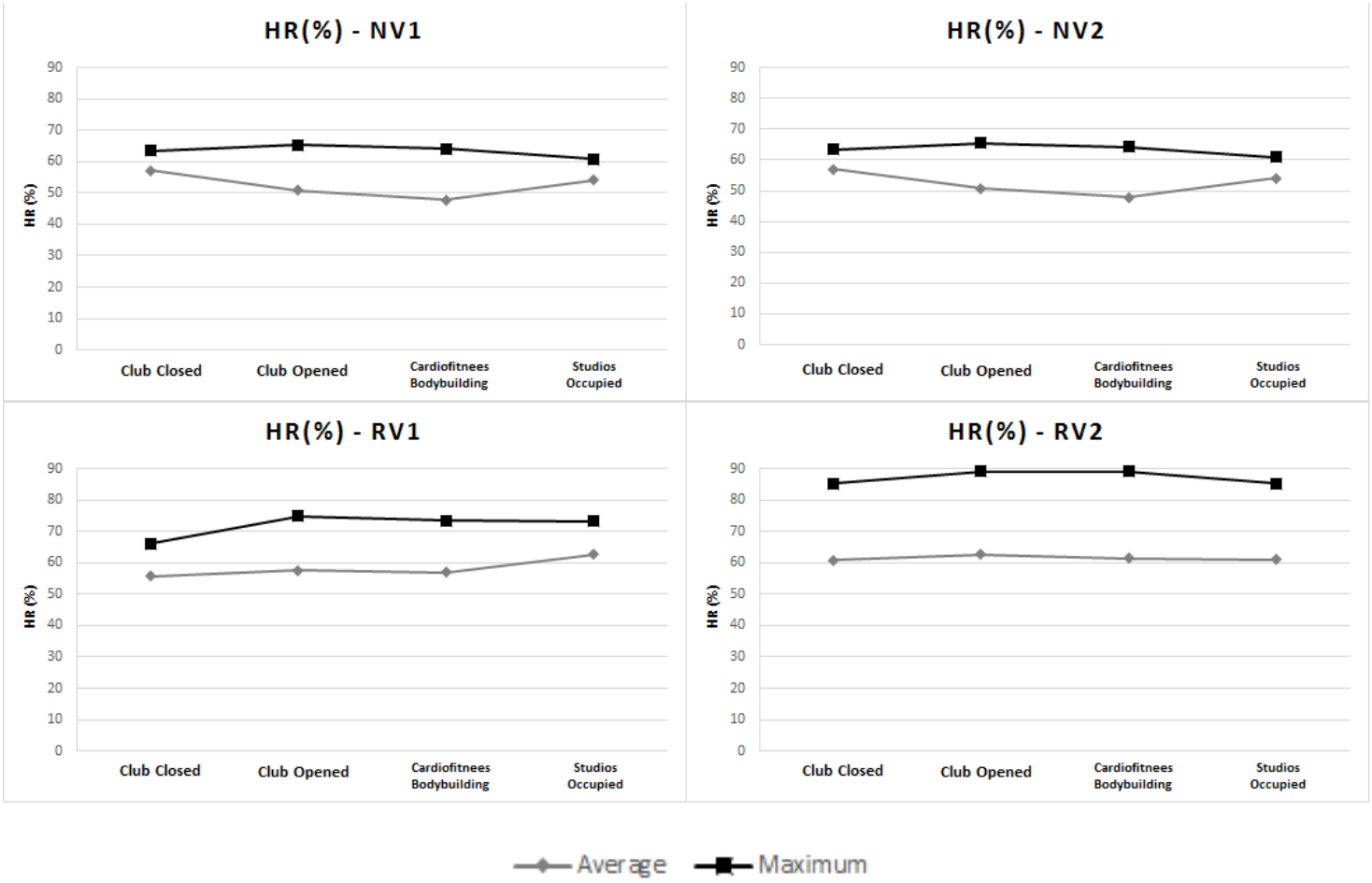

Figure 3. Relative humidity (\%) in four fitness clubs under normal ventilations (NV1, NV2) and under restricted ventilations and occupancy (RV1, RV2).

\section{CONCLUSIONS}

This study provides information on air quality in indoor $\left(\mathrm{CO}_{2}, \mathrm{~T}\right.$ and $\left.\mathrm{RH}\right)$ environments for sport practice, under different ventilations scenarios imposed due to limitation of COVID-19 pandemic. The restrictions in the number of occupants led to improved $\mathrm{CO}_{2}$ concentration, but the changes in ventilation did not favor the levels of comfort parameters, especially in group classes of greater activity intensity. Since regular exercise in environmental conditions, such as elevated T and increased RH can cause several health consequences (Sylvester et al., 2016; Racinais et al., 2012; Roelands et al., 2015), comfort parameters should be maintained within the recommended ranges by the proper use of air conditioning systems, isolation of the environment, reduction of sun / heat, even during restricted ventilation scenarios.

\section{ACKNOWLEDGMENTS}

This work received financial support by UIDB/50006/2020, UIDP/50006/2020, and by UIDB/00511/2020 of the Laboratory for Process Engineering, Environment, Biotechnology and Energy - LEPABE. Further funding was provided through the project PCIF/SSO/0017/2018 by the Fundação para a Ciência e a Tecnologia (FCT), Ministério da Ciência, Tecnologia e Ensino Superior (MCTES) through national funds. C. Peixoto would like to acknowledge FCT for her fellowship SFRH/BD/147185/2019.

\section{References}

Almeida, S.M., Silva, A.V., and Sarmento, S. (2014). Effects of Exposure to Particles and Ozone on Hospital Admissions for Cardiorespiratory Diseases in Setúbal, Portugal. Journal of Toxicology and Environmental Health, Part A, 77(1416), 837-848. http://dx.doi.org/10.1080/15287394.2014.887399 
American Society of Heating, Refrigerating, and Air-Conditioning Engineers (ASHRAE), ASHRAE Technical FAQ ID 92, Accessed online December 2019. Available at: https://www.ashrae.org/File\%20Library/Technical\%20Resources/Technical\%20FAQs/TC-02.01-FAQ-92.pdf

Bélanger, D., Gosselin, P., Valois, P., \& Abdous, B. (2014). Perceived Adverse Health Effects of Heat and Their Determinants in Deprived Neighbourhoods: A Cross-Sectional Survey of Nine Cities in Canada. International Journal of Environmental Research and Public Health, 11(11), 11028-11053. https://doi:10.3390/ijerph111111028

Castro, A., Calvo, A.I., Alves, C., Alonso-Blanco, E., Coz, E., Marques, L., Nunes, T., Fernández-Guisuraga, J.M., Fraile, R. (2015). Indoor aerosol size distributions in a gymnasium. Science of The Total Environment, 524-525, 178-186. https://doi.org/10.1016/j.scitotenv.2015.03.118

EEA. (2011). Environment and health. http://www.eea.europa.eu/themes/human.intro

Geng, Y., Ji, W., Lin, B., Zhu, Y. (2017). The impact of thermal environment on occupant IEQ perception and productivity. Building and Environment, 121, 158-167. https://doi:10.1016/j.buildenv.2017.05.022

Holmberg, U., Li, Y. (1998) Modelling of the indoor environment e particle dispersion and deposition, Indoor Air 8 113-122. ISSN 090S-6947.

IPMA. (2020). Boletim Climatológico Mensal - outubro 2020. ISSN 2183-1076.

Jin, H., He, C., Lu, L., Fan, J. (2013) Numerical investigation of the wall effect on airborne particle dispersion in a test chamber, Aerosol and Air Quality Research, 13: 786-794. https://doi.org/10.4209/aaqr.2012.04.0106

Pereira, M.C., Santos, R.C., Alvim-Ferraz, M.C.M. (2007). Air quality improvements using European environment policies: A case study of SO2 in a coastal region in Portugal. J. Toxicol. Environ. Health - Part A Curr. Issues 70. 1-5. https://doi.org/10.1080/15287390600884990

Persily, A.K. (1997). Evaluating building IAQ and ventilation with indoor carbon dioxide, ASHRAE Trans. 10 (2).

Racinais, S., Mohr, M., Buchheit, M., Voss, S.C., Gaoua, N., Grantham, J., Nybo, L. (2012). Individual responses to shortterm heat acclimatisation as predictors of football performance in a hot, dry environment. British Journal of Sports Medicine, 46(11), 810-815. https://doi:10.1136/bjsports-2012-091227

Ramos, C.A.; Wolterbeek, H.T. and Almeida, S.M. (2014). "Exposure to indoor air pollutants during physical activity in fitness centers". In Building and Environment, 82, 349-360. https://doi.org/10.1016/j.buildenv.2014.08.026

Ramos, C.A.; Reis, J.F.; Almeida, T.; Alves, F.; Wolterbeek, H.T. and Almeida, S.M. (2015). "Estimating the inhaled dose of pollutants during indoor physical activity". In Science of the Total Environment, 527-528, 111-118. https://doi.org/10.1016/j.scitotenv.2015.04.120

Roelands, B., De Pauw, K., Meeusen, R. (2015) Neurophysiological effects of exercise in the heat. Scandinavian Journal of Medicine \& Science in Sports, 25, 65-78. https://doi:10.1111/sms.12350

Satish, U., Mendell, M. J., Shekhar, K., Hotchi, T., Sullivan, D., Streufert, S., Fisk, W. (2012). Is CO2 an Indoor Pollutant? Direct Effects of Low-to-Moderate CO2 Concentrations on Human Decision-Making Performance. Environmental Health Perspectives 120 (12) 1671-1677. https://doi:10.1289/ehp.1104789

SEJD, Ginásios: Diploma relativo à construção, instalação e funcionamento, Available at Secretariat of State for Youth and Sport, Lisbon Portugal. Presidency of the Council of Ministers, Secretariat of State for Youth and Sport, 2008, http:// www.cd.ubi.pt/artigos/Gin\%C3\%A1sios.pdf

Slezakova, K.; Peixoto, C.; Pereira, M.C. and Morais, S. (2018). "Indoor air quality in health clubs: Impact of occupancy and type of performed activities on exposure levels". In Journal of Hazardous Materials, 359, 56-66. https://doi.org/10.1016/j.jhazmat.2018.07.015

Sylvester, J.E., Belval, L.N., Casa, D.J., O'Connor, F.G. (2016). Exertional heat stroke and American football: what the team physician needs to know. The American Journal of Orthopedics 45 (6) 340-348.

Warburton D., Nicol C., Bredin S. (2006). Health benefits of physical activity: the evidence. Canadian Medical Association Journal, 174(6), 801-809. https://doi:10.1503/cmaj.051351

Žitnik, M., Bučar, K., Hiti, B., Barba, Ž., Rupnik, Z., Založnik, A., Žitnik, E., Rodrìguez, L., Mihevc, I., Žibert, J. (2015). Exercise-induced effects on a gym atmosphere. Indoor Air, 26(3), 468-477. https://doi:10.1111/ina.12226 